\title{
Research on Implementation Paths of Rural Revitalization Strategy
}

\author{
Yu He ${ }^{1}$, Wenkuan Chen ${ }^{1, *}$ \\ ${ }^{1}$ Sichuan Agricultural University, Chengdu, 611130, China \\ *Corresponding Author: Wenkuan Chen
}

Keywords: Rural Revitalization, Path, Convergence, Green, Good governance

\begin{abstract}
Rural Revitalization Strategy is a major development strategy after the new era of socialism with Chinese characteristics. It is an important part of implementing the new development concept and building a modern economic system. Implementing the strategy of rural revitalization, fundamentally solving the "Three Rural Issues ", promoting agricultural development, rural prosperity, and increasing farmer's incomes is an important way to promote urban and rural prosperity and share the fruits of development. This paper discusses the implementation path of Rural Revitalization strategy, and puts forward concrete measures from four dimensions of integration, green, good governance and humanities.

In the new era of socialism with Chinese characteristics, the CPC Central Committee, with General Secretary Xi Jinping as its core, has put forward the strategy of Rural Revitalization based on a thorough understanding of the changing laws of urban-rural relations in the world and the laws of socialist construction with Chinese characteristics. This strategy is a major strategic plan which focuses on the overall situation of the Party and the state, and on the decision to build a well-off society in an all-round way and then realize the great goal of building a socialist modernization power. The strategy of Rural Revitalization is not only a development strategy of agricultural and rural areas, but also includes the overall development of urban-rural relations, industrial structure, social governance and other fields. It has an important impact on the sustainable development of the national economy. The implementation path must be practical and practical, focusing on practical results.
\end{abstract}

\section{Implement Rural Revitalization Strategy with Deep Convergence}

\subsection{Promote Development of Urban and Rural Spatial Integration}

Based on following the evolution law of rural population and industrial distribution and examining the future development trend, we should rationally layout the village structure, strengthen the construction of central and characteristic villages, and build a new village system with moderate scale, reasonable layout and integrated functions. To construct a new urban and rural residential and industrial system of "city + characteristic town + modern agricultural park / happy and beautiful new village" and reasonably undertake the transfer of urban functions, not only crack the disease of big cities, but also improve the carrying capacity of rural areas. We should make overall plans for rural production space, comprehensively consider the distribution and conditions of agricultural production resources, delimit and effectively protect permanent basic farmland, delimit and construct grain production functional zones and important agricultural product production protection zones, ensure food security and supply of important agricultural products, speed up the construction of characteristic agricultural product advantage zones, and promote the improvement of agricultural quality and efficiency. We should increase income with farmers, strengthen the construction of rural industrial parks, and support the development of new rural industries and new formats. Control rural living space, strengthen planning and management, comprehensively carry out county (city) regional rural construction planning and village planning, improve the binding force, overall arrangement of 
rural housing, important infrastructure and public service facilities space.

\subsection{Promote Convergence Development of the Primary Industry, Secondary Industry, the Tertiary Industry}

Efforts should be made to develop the second industry of the countryside as an important pillar to realize the comprehensive revitalization of the rural industry. Strengthen the primary processing of agricultural products, around the characteristics of agricultural products to carry out the primary processing of origin, speed up the construction of primary processing facilities, so that the main agricultural production to share more value-added benefits of industry. We will vigorously develop the intensive processing of agricultural products and increase the driving force for the development of characteristic processing industries. According to the regional characteristic superiority industry, we should construct the agricultural product processing concentrated area, accelerate the characteristic food processing industry demonstration base construction, and promote the agricultural production base construction by the agricultural product processing. Vigorously develop leisure and tourism oriented rural tourism. Vigorously develop cultural and creative agriculture, cultivate several creative agricultural products, creative farmland landscape, creative local culture, creative housing, create characteristic cultural towns, ecological and cultural towns, build agriculture + cultural and creative industries. Promote the construction of the tertiary industry service system, cultivate and improve the rural market system, and accelerate the development of rural e-commerce, logistics, trade and other industries.

\subsection{Promote Integration Development of Public Service and Infrastructure in Urban and Rural Areas}

We should speed up the construction of infrastructure and public service supply mechanism that is compatible with the transformation of rural development mode. According to the general trend of rural population structure, development demand and urban-rural relationship changes, the rural public goods supply system should be reformed, and a modern public goods supply system should be established which is suitable for rural spatial distribution, demand subject and demand content. Rationally distinguish the difference between the supply of living public goods and the supply of productive public goods in the aspects of demand subject, demand content and input mode. For living public goods, a multi-level supply structure of "central village (town) - rural community - agricultural residence" should be established. To scientifically plan the content of public goods supply, we should not only meet the actual needs of rural development, but also avoid over-supply and ineffective supply. For productive public goods, we should establish a supply system with the overall development of the industry as the goal and orientation, reduce the investment in the operation of a single subject, and increase the investment in products with the nature of public demand in the process of regional industrial development. We should make full use of modern information technology to improve the efficiency of rural infrastructure and public service management. Through the "big data" to grasp the trend of urban and rural population mobility and the overall characteristics of public service demand, according to the changes in rural population and the actual needs of rural development, more precise supply of public goods, for the formation of a "money with people" public goods supply system to provide precise targeting. With the help of modern information technology, the mode of "Internet + rural public service" has been established to form the function of community public information dissemination, data collection and interest expression based on Internet.

\section{Implement Rural Revitalization Strategy with Green Development}

\subsection{Promote Agriculture Green Production}

We should carry out actions to reduce agricultural inputs. With the increasing "hollowing" and "aging" in rural areas, extensive and short-term production methods of excessive application of fertilizers, pesticides and herbicides are becoming increasingly common. In the process of promoting 
rural revitalization, it is necessary to improve the quality assurance ability and sustainable development ability of agricultural products from the source of agricultural production. We should promote the reduction of agricultural inputs, especially the "zero growth" of chemical fertilizers and pesticides, strengthen soil testing and formula fertilization, promote the transformation and upgrading of the single fertilizer industry, and promote the replacement of chemical fertilizers with organic fertilizers. Speed up the standardization and brand building of agriculture. Efforts should be made to raise the level of agricultural standardization, especially to strengthen the construction of "three products and one standard" bases, and to raise the ecological standards of agricultural development by means of green and organic production standards. We should create safe and high-quality regional public goods brands for agricultural products, transform ecological advantages into development advantages and competitive advantages, tightly integrate ecological poverty alleviation with poverty alleviation, and increase the added value of agricultural products by developing high-quality ecological characteristics.

\subsection{Strengthen Rural Environmental Management and Ecological Protection}

We must vigorously strengthen the comprehensive improvement of rural environment. To carry out the comprehensive improvement of rural human settlements, we should highlight the three revolutions of rubbish treatment, sewage treatment and toilet renovation in rural areas, carry out the construction mode of combining pollution control with resource utilization, engineering measures with ecological measures, concentration and decentralization, and improve the classification and treatment mechanism of rural domestic refuse. It is necessary to combine the development of courtyard economy with the optimization of courtyard environment, eliminate the disorderly construction and pile up, improve the living environment, and highlight the local characteristics and regional industrial characteristics. Accelerate the improvement of ecological compensation mechanism. Further exploration and expansion of the field and scope of ecological compensation should be focused on improving the ecological compensation mechanism of drinking water source protection areas, wetland ecological benefit compensation mechanism, forest ecological benefit compensation mechanism, forming the operation mechanism of ecological damage compensation, beneficiary payment, and protector reasonable compensation, and strengthening the inherent ecological environment. We will improve the participation mechanism in the construction of rural ecological civilization and enhance the initiative and enthusiasm of the public to participate in the construction of rural ecological civilization.

\subsection{Deepen Evaluation System of Green Development}

We should improve the green assessment system for economic and social development. We should strengthen the scientific and technological support of green development evaluation, establish an early-warning system for monitoring agricultural resources, environment and ecology, and explore a production cost accounting mechanism that fully reflects the degree of scarcity and loss of resources. We will improve the environmental protection and management system, reform the ecological environment supervision system, improve the law enforcement responsibility system, incorporate the monitoring and control of rural non-point source pollution into the annual assessment, and improve the green assessment system for economic and social development. We will improve the incentive policy system for green development of agriculture. Focusing on cultivated land protection compensation, ecological compensation system and green financial incentive mechanism, we should speed up the establishment of a scientific classification, regional differences, reasonable standards, standardized and unified agricultural green development incentive policy system to guide and encourage producers to accelerate the transformation of development mode. The results of ecological environment protection should be included in the annual assessment and daily assessment as an important reference for the comprehensive evaluation of local government leading groups and leading cadres, and should be fully applied to the work of team allocation, cadre selection, re-election inspection, evaluation of merit and award. 


\section{Implement Rural Revitalization Strategy with Good Governance}

\subsection{Strengthen Party Building at the Grassroots Level}

The grass-roots party organization is the core and key of rural governance. In the process of promoting rural revitalization, we should, in particular, aim at the weaker shortcomings of some grass-roots Party organizations, improve the "one-core and multiple" village-level governance structure with the village Party organizations as the core and the villagers 'committees, village affairs supervision committees, collective economic organizations and social organizations participating extensively, so as to effectively promote the return of the functions of various governance bodies. . Establish and improve the joint meeting system of village affairs and the village (residential) people's deliberation system, improve and implement the system of regular hearing reports from villagers' committees by the village Party organizations, promote the coordinated governance mechanism of the party building to promote the construction of various types of organizations at the village level, and build a scientific leadership system of village organizations. Strengthen the Party organization as the core leading mass deliberation and consultation, leading a pluralistic body to carry out services, coordinate the participation of all parties in governance, promote the village Party organization Secretary full-time, the first secretary normalization and institutionalization, accelerate the appointment of organs, institutions (universities) and state-owned enterprises in the outstanding talent as village Party organization secretary.

\subsection{Strengthen Village Autonomy}

Village autonomy is an important embodiment of the people-centered development thought. To promote good governance in rural areas and achieve effective governance, we must give full play to the status of the villagers as masters and the key role. We should carry out the working procedures of democratic villages, such as "four conferences, two openings and one supervision" and implement the separation of autonomous organizations from collective economic organizations in an all-round way. We should strengthen the construction of village affairs supervision committee and improve the practical and effective supervision mechanism of village affairs. We should speed up the pilot construction of village 'autonomy, explore new rural governance models in areas where conditions are ripe, incorporate the forward-looking factors of two-way flow of urban and rural population and mixed residence into the rural governance structure. We should strengthen the construction of community governance system, promote community service management, and explore the construction of rural resident self-government service management mechanism under the leadership of village Party organizations. We should improve the construction of comprehensive information platform for open service at the village level, speed up the realization of network interconnection, data interchange, information sharing, and promote accurate docking between grass-roots service system and meeting the diverse needs of the masses.

\subsection{Deepening Legalization in Countryside}

Based on deepening the implementation of the special action of combating illegal activities and eliminating evil, we should focus on deepening the rule of law in rural areas in view of the phenomena of non-compliance with the law and lax enforcement of the law in the agricultural and rural areas. It is necessary to clarify the boundaries of responsibilities and the division of powers of rural grass-roots Party organizations, grass-roots governments, autonomous organizations, social organizations and collective economic organizations participating in community development and governance in accordance with the law, and to establish a working mechanism with reasonable distribution of powers, clear responsibilities and efficient and coordinated operation. We should speed up the construction of rural legal service system, promote legal aid to villages and legal counsel into villages. We should establish and improve the basic level judicial service facilities in rural areas and expand the coverage of Judicial Services at the grass-roots level in rural areas. We should improve the system of prevention and control of public order in rural areas, establish and improve the people's mediation committees at the village level, and set up various professional mediation 
organizations in rural areas. We should work out a way to evaluate the performance of the rule of law in rural areas to ensure the smooth development of various undertakings in rural areas.

\subsection{Innovate Rural Rule of Virtue}

Rule of virtue is the emotional support to achieve good governance in rural areas. For a long time, the patriarchal society and social characteristics of human relations in rural areas are obvious. Rule of virtue plays an irreplaceable and unique role in rural governance. To a certain extent, the promotion of good governance by virtue is the inherent demand of rural development, but also the effective sublimation of rural governance. We should promote the construction of honesty and credit, and strengthen the sense of integrity, responsibility and rules in rural areas. Correctly guide and play the role of "civilized Township virtuous" in rural governance, for the settlement of rural contradictions and disputes, public services and public welfare construction to play a consultative and coordinated role. We should establish and improve the community moral evaluation mechanism, carry out family training and family education, advocate civilized cultivation, eliminate stereotypes and bad habits, eradicate feudal superstitions, ecological funerals and other activities, guide rural residents to worship virtue, realize the benign interaction of resident autonomy, and form a "three Communist" pattern of social governance and mutual governance. Autonomy, rule by law, rule by virtue, "Three Combinations" is a new mode of rural governance.

\section{Implement Rural Revitalization Strategy with Humanistic Promotion}

\subsection{Enhance Civilization Quality of Farmer}

In view of the rural young and middle-aged going out in large numbers, the aging phenomenon of the left-behind personnel is prominent, and the characteristics of relatively low cultural level, vigorously improve the civilized accomplishment of rural residents. Guided by Xi Jinping's thought of socialism with Chinese characteristics in the new era, we should carry out the regular education and propaganda work of socialist core values, so as to enhance rural resident understanding of socialist core values in a concrete and life-oriented way. We should deepen the socialist core values into all aspects of rural construction, and promote the socialist core values to take root in rural areas. We should combine the work of fighting poverty with the construction of the "four good villages" to strengthen the construction of rural culture and civilization, let the peasants form good habits and good habits, effectively curb the old and bad habits such as rubbing banquets and extravagant waste in rural areas, and consciously resist the erosion of decadent culture and backward culture. It is necessary to publicize policies, popularize wealth-making skills and disseminate new civilizations through evening schools and mobile workshops for farmers.

\subsection{Enrich Cultural Life of Village}

Since rural cultural life is relatively scarce, based on the actual needs and psychological characteristics of rural population, rural cultural life is carried out in a variety of flexible forms. Organize rural elegant singing and dancing performances, featured sports competitions, folk customs exhibitions, featured festivals and other activities to explore the depth of rural traditional culture, and with the help of modern information technology to present it, the formation of traditional culture and modern civilization organic combination of rural cultural activity system. We should deepen the building of mass spiritual civilization and continue to break down feudal superstitions, especially by taking "village rules and regulations", "family discipline" and "civilized building" as our grasp, and promoting rural spiritual civilization through such selection activities as "civilized families" and "civilized townsmen", "good neighbors", "good parents-in-law", "good daughter-in-law" and "good children". Develop in harmony with material civilization.

\section{References}

[1] Su Yiqing, You Yuting, Wang Zhigang. Convergence Development of Primary, Secondary and 
Tertiary Industries: Theoretical Discussion, Situation Analysis and Suggestions [J]. China Soft Science, 2016(8): 17-28.

[2] Yang Jianli, Xing Jiaoyang. The Convergence Development of Agriculture, Second Industry and Third Industry in Rural Area of China [J]. Chinese Journal of Agricultural Resources and Regional Planning, 2017, 38(9): 72-78.

[3] Cao Yixia, Geng Haoyi. The Empirical Study on Industry Convergence Structure among Urban Agriculture Industry, Secondary Industry and Tertiary Industry in Shanghai: Based on Comparative Analysis of Input-Output Table [J]. Fudan Journal (Social Sciences), 2018(4): 149-157.

[4] Tang Shuzhuan. Development of Leisure Agriculture Tourism Resource of Henan Province Basing on Industry Convergence Theory [J]. Chinese Journal of Agricultural Resources and Regional Planning, 2016, 37(3): 221-224. 